\section{Autofluorescence and Diagnostic Accuracy of Lesions of Oral Mucosa: A Pilot Study}

Enric Jané-Salas ${ }^{1}$, Andrés Blanco-Carrión², Lluís Jover-Armengol ${ }^{3}$, José López-López ${ }^{1}$
'Department of Dentistry and Stomatology, University of Barcelona, Catalonia, Spain ${ }^{2}$ University of Santiago de Compostela, Santiago de Compostela, Spain ${ }^{3}$ University of Barcelona, Catalonia, Spain

Correspondence: José LópezLópez, C/Feixa Llarga s/n 08907, L'Hospitalet de Llobregat, Barcelona, Catalonia, España. Tel: +34-60645-7362. e-mail: 18575jll@gmail. com; enricjanesalas@ub.edu
The purpose of this study was to determine the accuracy of autofluorescence techniques for diagnosing oral mucosa lesions, using as reference pattern for comparison the visual diagnosis made by a clinical specialist. A pilot study was conducted with 60 patients divided in a control group without mucosal pathology and a study group with known clinical history for mucosal pathology. Both groups were examined by an oral medicine specialist and by a general dentist who used VELscope ${ }^{\circledast}$ system, which applies tissue fluorescence visualization to identify oral mucosal abnormalities. Using the VELscope system, the general dentist made overdiagnosis in two cases and underdiagnosis in one case. The sensitivity and specificity for the oral medicine specialist were 1 ( $95 \% \mathrm{Cl}: 0.884$ to 1). For the general dentist, the sensitivity did not improve significantly with the use of VELscope ${ }^{\circledast}$ system [0.53 (95\% Cl: 0.343 to 0.717 ) versus 0.49 ( $95 \% \mathrm{Cl}: 0.406$ to 0.773 )] and the specificity was 0.80 (95\% Cl: 0.614 to 0.923$)$. A limitation of the study is the small sample size, which does not fully represent a population and extrapolation of the data should be done carefully. Based on the obtained results, no clinical benefits were obtained using this VELscope ${ }^{\circledast}$ system.
Key Words: autofluorescence, cancer, pre-cancer, early diagnostic, VELScope ${ }^{\circledR}$.

\section{Introduction}

The early detection of diseases in the oral mucosa and potentially malignant disorders (1) requires a careful tracking of potentially malignant lesions given the high frequency of malignant transformation and has critical importance regarding a patient's best interest (2). Prognosis depends widely on the stage of the pathologies when detected and treated, and so early detection is the most effective method to reduce morbidity and mortality.

In the last few decades, given the importance of early detection of premalignant dysplasia or oral cancer, some complementary diagnostic systems were introduced to improve and facilitate the identification of oral lesions and subjacent oral diseases, such as VELscope ${ }^{\circledast}$ (Visually Enhanced Lesion Scope) system (3). This hand-held device developed by LED Dental Inc., a wholly-owned US subsidiary of LED Medical Diagnostics Inc., White Rock, BC, Canada) in association with British Columbia Cancer Agency, uses the basic premise of tissue fluorescence visualization, which is identifying changes in oral mucosal tissues by observing the fluorescence of oral tissues in response to light excitation. This system detects the loss of fluorescence in visible and not visible high-risk lesions using a handpiece emitting light at 400-460 nm wavelength range. Under this light, the normal mucosa emits green color fluorescence while the abnormal area absorbs the fluorescent light and dark patches appear. Therefore, it detects the early biochemical changes in oral disease and, theoretically, allows the early detection of pathological lesions. The VELscope ${ }^{\circledast}$ system sends a blue light into the oral cavity, which excites the surface of the epithelium through the basement membrane and stroma, causing fluorescence. The clinician is then able to see immediately the different kinds of fluorescence response, which aids distinguishing the contrast between normal and abnormal tissue $(4,5)$.

The physiopathological concept that explains tissue autofluorescence response is based on changes in the cell structure (such as hyperkeratosis, hypercromatine, increase in pleomorphism, variations in nucleus size and even cell volume) and metabolism (concentration of flavin adenine and nicotinamide adenine dinucleotide in epithelial and in subepithelial stroma). In particular, these changes in the epithelium and in the stroma, may alter the distribution of the fluorophores in the tissues and consequently the way by which the fluorescence is emitted after been stimulated by the blue light $(2,6)$. Hemoglobin strongly absorbs the autofluorescent light produced by collagen and elastin. More specifically, the increased presence of submucous blood associated with oral cancer and its angiogenesis process may enhance the absorption of collagen and elastin produced by the autofluorescent light, this is why the area may appear darker during the examination with VELscope ${ }^{\circledast}(7-10)$.

The use of autofluorescence for detection of malignant 
lesions was provided by photodynamic therapy, a technique used clinically to treat cancer. During this therapy, the lightsensitive drug (photosensitizer) is introduced in the tumour either by systemic or local application using a precursor such as protoporphyrin IX. The photosensitizer produces free oxygen which, when excited by light application at specific wavelength, damages the cell organelles causing cell death. It is believed that certain sensitizers accumulating in malignant tissues can be useful for its diagnosis.

By the end of 1970, autofluorescence, also known as endogenous fluorescence of the tissues, was employed for detection of the exogenous fluorescence that could be useful for the detection of cancer (11). Moreover, it has been used for the early detection and diagnosis of precancer and cancer lesions in lungs, cervix, skin and more recently, the oral cavity.

Tissue fluorescence visualization systems can be helpful to detect a wide variety of premalignant and malignant lesions in addition playing a crucial role in the delineation of the surgical margin, treatment and even follow-up $(8,12)$.

The aim of this study was to determine if the use

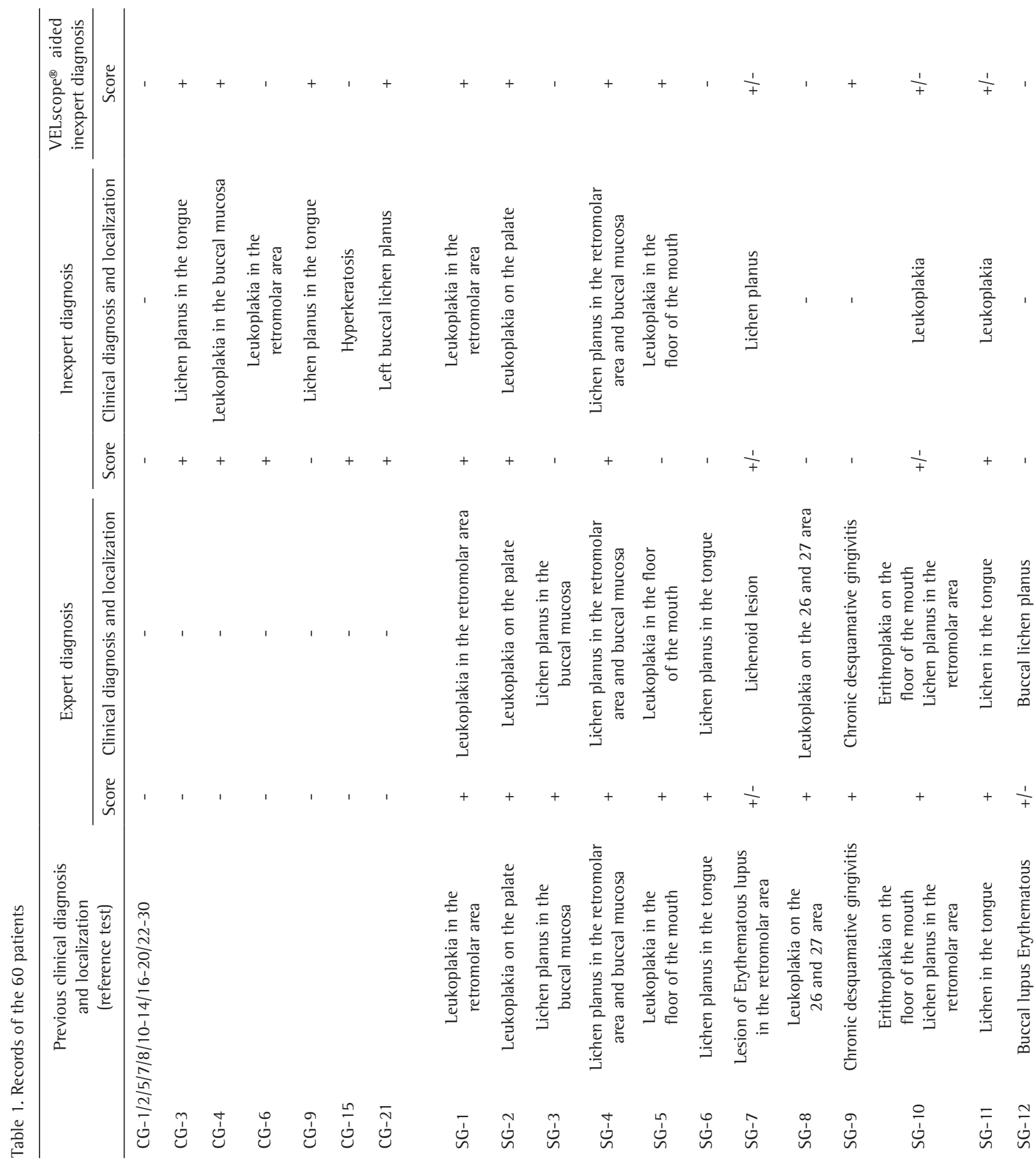


of VELscope ${ }^{\varpi}$ for diagnosis of oral mucosa lesions may improve the diagnostic accuracy when compared with direct clinical examination. Another goal was to define the role of systematic and meticulous clinical examinations as useful tools in the diagnosis of oral lesions.

\section{Material and Methods}

A validation of the study was carried out and it was approved by the ethics committee of the Dental School, University of Barcelona and the University Hospital of Bellvitge. The protocol number of the ethics committee of the University Hospital of Bellvitge is PR049/10 dated
08/07/2010.

\section{Study Population and Sample}

This study was carried out with two groups of 30 patients with or without previous diagnosed pathology in the mucosa of the oral cavity. A convenience sampling scheme was used by reviewing the clinical history of all patients who attended the Dental Clinic of the University of Barcelona and had been previously treated at the Master degree Programs of Dental Surgery and/or Oncology and Immunocompromised Patients of the University of Barcelona, Spain. The patients were informed about the purpose of the study, agreed to participate voluntarily and signed an informed consent form. Patients with confirmed diagnosis of squamous cell carcinoma; with injuries or biopsy surgeries of suspicious areas; with clinical and/or previous histopathological diagnosis of oral carcinoma; with a diagnosis of lesion of unknown origin or confirmed or highly suspected malignancy, were not included.

The study group (thereafter SG) was formed by recruiting the first 30 patients with a diagnostic record in their clinical history of some oral pathology. All suspicious lesions were diagnosed by biopsy and histopathology. The control group (thereafter $\mathrm{CG}$ ) was also formed by recruiting the first 30 patients without any previous record of oral mucosal disease in their clinical history. Thus, information about the presence of oral mucosa pathology from patient's clinical history was used as a reference diagnostic parameter. The study was performed between the beginning of June and the end of July, 2013.

\section{Main Variables}

a) Expert diagnosis (made by an oral medicine specialist); b) Inexpert diagnosis (made 
by a general dentist) and; c) VELscope ${ }^{\circledR}$ aided inexpert diagnosis. All three outcomes were originally recorded as positive (+): some oral mucosa pathology detected), negative (-): no oral mucosa pathology detected) and doubtful (+/-): no definitive decision was made. For the analysis and comparisons of diagnostic accuracy, original doubtful scores were reassigned as positive (+).

\section{Secondary Variables}

Size and location of the detected lesions by both examiners and the VELscope ${ }^{\circledR}$ system.

\section{Systematization of the Study}

The same evaluation protocol was followed for all patients. Both examiners (expert and inexpert) were blinded to group assignment, did not have access to the patient's clinical history and did not carry out patient anamnesis.

\section{Expert Diagnosis}

An experienced specialist examiner (J.L.L.) with more than 5 years of experience in the diagnosis of oral pathologies carried out a detailed and rigorous examination of the oral cavity, emphasizing the presence of lesions or changes in the surface of the tissues. The presence of lesions and their location were recorded with the aid of the diagram proposed by Roed-Petersen and Renstrup (13) and a clinical diagnosis was established. To compare and reproduce the obtained data as well produce a detailed mapping of oral cavity, pictures of the suspicious areas and other locations were taken using a Sony model $\alpha 350$ (Tokyo, Japan): 1. Retromolar right area, 2. Retromolar left area, 3. Right oral mucosa, 4. Left oral mucosa, 5. Dorsal tongue, 6 . Right border of the tongue, 7. Left border of the tongue, 8. Floor of the mouth, 9. Upper vestibular gingival, 10. Lower vestibular gingival. .

\section{Inexpert Diagnosis}

An examiner (F.D.L) with more than 2 years of experience since graduation and blinded to the expert diagnosis, proceeded with an exhaustive exploration of the oral cavity looking for the presence of any alterations or lesions. The presence of lesions and their location were recorded with the aid of the diagram proposed by Roed-Petersen and Renstrup (13) and a clinical diagnosis was established. Pictures of the suspicious areas as well as the other locations were taken, as previously mentioned.

\section{VELScope ${ }^{\circledR}$ Aided Inexpert Diagnosis}

Immediately after the previous examination, the same non-specialist examiner, who had received training on the use of the device, explored the oral cavity using VELScope ${ }^{\circledR}$, in a environment with no kind of illumination (Fig. 1). The presence of lesions and their location were recorded with the aid of the diagram proposed by Roed-Petersen and
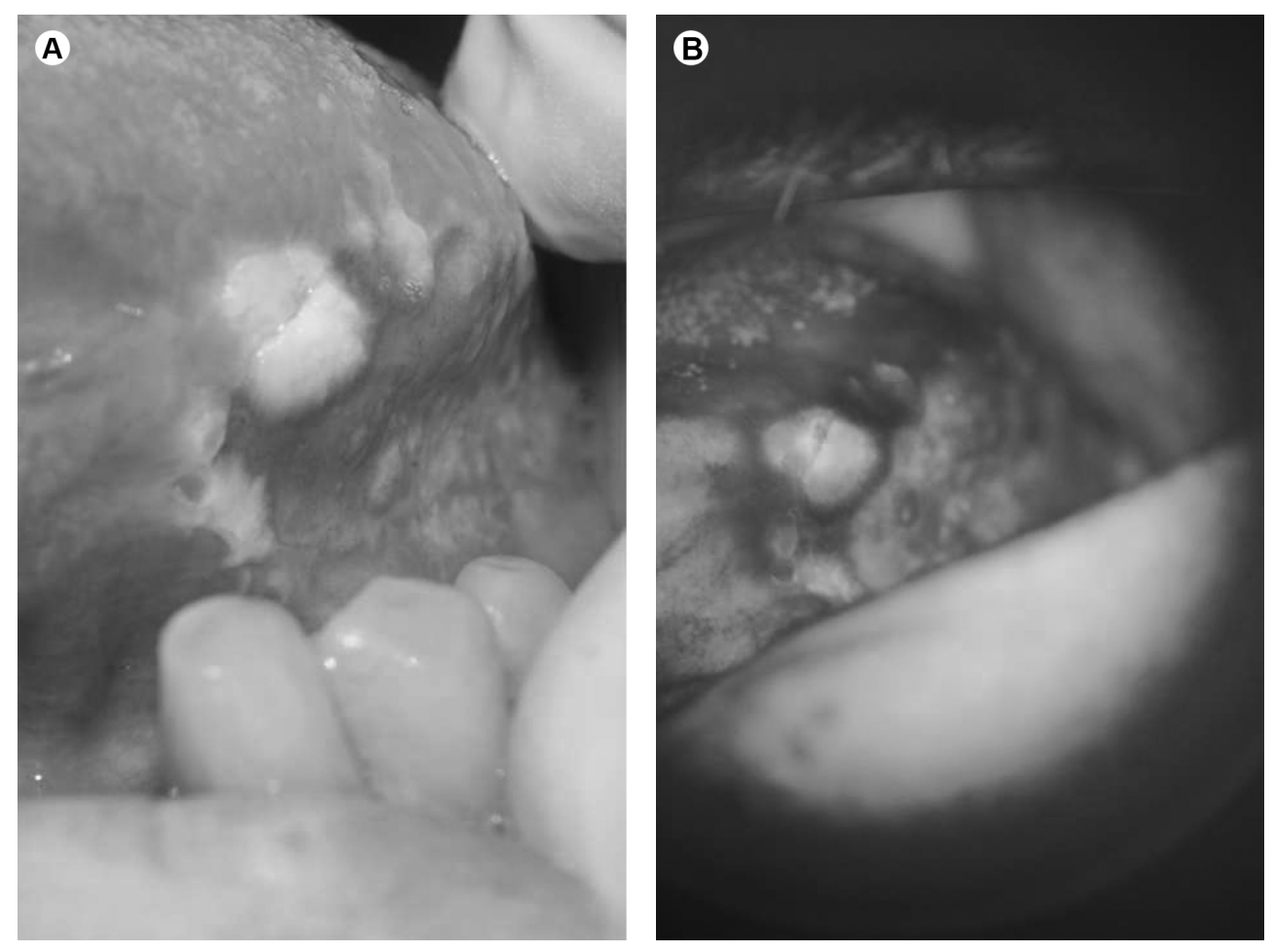

Figure 1. A: Clinical image of the lesion. B: Visualization with VELscope ${ }^{\circledR}$. 
Renstrup (13) and a clinical diagnosis was established. Pictures of the suspicious areas as well as the other locations were taken, as previously mentioned.

\section{Statistical Analysis}

Confidence intervals for proportions were estimated using Clopper-Pearson exact procedure (14). Agreement between diagnostic procedures was assessed using Cohen's kappa statistic. McNemar test for paired proportions with Montecarlo approach were also used. Statistical analyses were carried out using PASW v. 18.0 software. The STARD checklist was applied for reporting of studies of diagnostic accuracy (version January 2003)(15).

\section{Results}

Summary of the recorded data is shown in Tables 2 and 3. Regarding diagnostic accuracy, the estimated values for sensitivity and specificity were both 1 (95\% $\mathrm{Cl}$ : 0.884 to 1) for expert diagnosis. Performance of inexpert diagnosis decreases, showing a 0.53 sensitivity $(95 \% \mathrm{Cl}: 0.343$ to 0.717 ) and 0.83 specificity (95\% $\mathrm{Cl}: 0.653$ to 0.944 ). With the use of VELscope ${ }^{\circledR}$ the diagnostic performance of the inexpert examiner is not improved, obtaining a sensitivity

Comparing the proportion of positive diagnostics between unaided and VELscope ${ }^{\circledR}$ aided inexpert diagnosis we found that there is no significant difference in the paired proportions (McNemar chi-square $=1.3$, montecarlo $p$-value $=0.45$ ).

\section{Discussion}

The clinical examination of the oral tissues delivers diagnosis, which needs to be confirmed by the histopathological examination of biopsied tissue samples. For this reason, a wide variety of studies have tried to assess the effectiveness of the VELscope ${ }^{\circledR}$ system as an adjuvant of visual examination to improve the detection of lesions. Among them is the series of 112 patients examined by Farah et al. (16), the clinical examination using VELScope ${ }^{\circledR}$ showed a sensitivity of $30 \%$ and a specificity of $63 \%$. Its accuracy at identifying dysplasia was $55 \%$. Our study shows that, based on the sensitivity and specificity, VELscope ${ }^{\circledR}$ aided diagnosis does not appear to be more accurate than unaided clinical exploration. However, with regards to identifying lesions invisible to naked eye in the clinical examination, promising results have been shown using this method $(4,9,17)$.

Another author (18) reported that there was no evidence that the use of VELscope ${ }^{\circledR}$ in the routine clinical practice could be a measure to save lives by establishing an early diagnosis. Instead, he emphasizes that the adoption of this system for the diagnosis of cancer can be premature because it does not distinguish malignant from benign lesions, which may cause many false positives, causing insecurity and stress among patients.

In a recent study, the results using Vizilite ${ }^{\circledR}$ and

Table 3. Estimates of diagnostic accuracy indices for the three diagnostic evaluations

\begin{tabular}{llcc}
\hline Accuracy index & & $\begin{array}{c}\text { Point } \\
\text { estimate }\end{array}$ & $\begin{array}{c}95 \% \text { Confidence } \\
\text { interval }\end{array}$ \\
\hline Expert diagnosis & Sensitivity & 1.00 & $0.88-1.00$ \\
& Specificity & 1.00 & $0.88-1.00$ \\
Inexpert diagnosis & Sensitivity & 0.53 & $0.34-0.72$ \\
& Specificity & 0.83 & $0.65-0.94$ \\
Velscope-aided & Sensitivity & 0.40 & $0.41-0.77$ \\
inexpert diagnosis & Specificity & 0.80 & $0.61-0.92$ \\
\hline
\end{tabular}

Table 2. Summary table of diagnostic assignment in three categories (+ with lesion, +/-doubt and - without lesion) obtained from three independent evaluations on 60 examined individuals

\begin{tabular}{|c|c|c|c|c|c|c|c|c|c|c|}
\hline \multirow{2}{*}{ Reference test } & & \multicolumn{3}{|c|}{ Expert diagnosis } & \multicolumn{3}{|c|}{ Inexpert diagnosis } & \multicolumn{3}{|c|}{ Velscope-aided inexpert diagnosis } \\
\hline & & + & $+1-$ & - & + & $+1-$ & - & + & $+1-$ & - \\
\hline \multirow{2}{*}{$\begin{array}{l}\text { Study Group } \\
\text { (with lesion) }\end{array}$} & count & 26 & 4 & 0 & 9 & 7 & 14 & 10 & 8 & 12 \\
\hline & $\mathrm{n}=30$ & $(0.87)$ & $(0.13)$ & $(0.0)$ & $(0.30)$ & $(0.23)$ & $(0.47)$ & $(0.33)$ & $(0.27)$ & $(0.40)$ \\
\hline \multirow{2}{*}{$\begin{array}{l}\text { Control Group } \\
\text { (without lesion) }\end{array}$} & count & 0 & 0 & 30 & 5 & 0 & 25 & 6 & 0 & 24 \\
\hline & $\mathrm{n}=30$ & $(0.0)$ & $(0.0)$ & $(1.0)$ & $(0.17)$ & $(0.0)$ & $(0.83)$ & $(0.20)$ & $(0.0)$ & $(0.80)$ \\
\hline \multirow{2}{*}{ Total } & count & 26 & 4 & 30 & 14 & 7 & 39 & 16 & 8 & 36 \\
\hline & $n=60$ & $(0.43)$ & $(0.07)$ & $(0.50)$ & $(0.23)$ & $(0.12)$ & $(0.65)$ & $(0.27$ & $(0.13)$ & $(0.60)$ \\
\hline
\end{tabular}


VELscope ${ }^{\circledR}$ compared with histopathological analysis showed poor sensitivity and no significant predictive value in both systems. The false negative results were very high. Furthermore, researchers revealed that after the negative results provided by ViziLite ${ }^{\circledR}$ and VELscope ${ }^{\circledR}$, which did not always coincided with the histopathological diagnosis, there was a feeling of insecurity for the clinician and the patient (11). Regarding the limitations of these studies, they diverge from the types of lesions included, since they were carried out among patients with the diagnosis of squamous cell carcinoma or severe dysplasia, confirmed by biopsy. In addition, the samples were small and were performed in the same center.

In the present study, as the sample was composed of a small group, it does not fully represent a population and extrapolation of the data should be done carefully. Furthermore, our findings agree with other authors' opinion regarding the need of previous training, which, combined with the difficulty of taking pictures with this system, makes it difficult to use on a daily basis in general practice $(3,17,19-22)$.

Farah (16) found adequate sensitivity and specificity, disagreeing with other studies, ours included, that observed worse results for the autofluorescence system $(11,18)$. We think that a well-trained human eye provides, as demonstrated in our comparative study, results that are difficult to improve by complementary optical methods, which are also very technique-sensitive. For these reasons we think that training the dentist in oral pathology is essential as a method of screening for premalignant lesions.

The World Health Organization (WHO) has clearly determined that early diagnosis is the best way to prevent and control oral cancer. Many authors agree that the use of devices that aid visualization can help identifying the margins of the lesion and its extension when an unmagnified view is not available. The findings of this study corroborate the discussions on the literature that previous training is necessary before operating autofluorescence devices, therefore it was difficult to obtain quality pictures for our records.

From the results of the present study, no clinical benefits were obtained from the use of VELscope ${ }^{\circledR}$ system.

\section{Resumo}

0 objetivo deste estudo foi determinar a precisão das técnicas de autofluorescência para o diagnóstico de lesões da mucosa oral, utilizando como padrão de referência para comparação o diagnóstico visual feito por um especialista clínico. Um estudo piloto foi realizado com 60 pacientes, divididos em um grupo controle sem patologia da mucosa oral e um grupo de estudo com história clínica conhecida de patologia da mucosa oral. Ambos os grupos foram examinados por um especialista em medicina oral e por um dentista clínico geral que usou o sistema VELscope ${ }^{\circledR}$, que aplica a visualização por fluorescência para identificar anormalidades do tecido da mucosa oral. Usando o sistema
VELscope ${ }^{\circledR}$, o dentista geral realizou sobrediagnóstico em dois casos e subdiagnóstico em um caso. A sensibilidade e especificidade para o especialista em medicina oral foi 1 (IC 95\%: 0,884 a 1). Para o dentista geral, a sensibilidade não melhorou significativamente com o uso do sistema de VELscope ${ }^{\circledR}[0,53$ (95\% $\mathrm{Cl}$ : 0,343 to 0,717) versus 0,49 (95\% $\mathrm{Cl}: 0,406$ to 0,773 )], e a especificidade foi de 0,80 (IC de $95 \%: 0,614-$ 0,923). Uma limitação do estudo é o pequeno tamanho da amostra, que não representa totalmente a população e a extrapolação dos dados deve ser feita com cuidado. Com base nos resultados obtidos, não houve benefícios clínicos com o uso do sistema VELscope ${ }^{\circledR}$.

\section{References}

1. Warnakulasuriya S, Johnson NW, van der Waal I. Nomenclature and classification of potentially malignant disorders of the oral mucosa. J Oral Pathol Med 2007;36:575-580.

2. Epstein JB, Villines D, Drahos G, Kaufman E, Gorsky M. Oral lesions in patients participating in an oral examination screening week at an urban dental school. J Am Dent Assoc 2008;139:1338-1344.

3. Patton LL, Epstein JB, Kerr AR. Adjunctive techniques for oral cancer examination and lesion diagnosis: a systematic review of the literature. J Am Dent Assoc 2008;139:896-905.

4. LED Dental Inc. Velscope: the oral cancer screening system. Available at: www.velscope.com. Accessed on 12/10/2014.

5. Trullenque-Eriksson A, Muñoz-Corcuera M, Campo-Trapero J, CanoSanchez J, Bascones-Martinez A. Analysis of new diagnostic methods in suspicious lesions of the oral mucosa. Med Oral Patol Oral Cir Bucal 2009;14:210-216.

6. Svistun E, Alizadeh-Naderi R, El-Naggar A, Jacobs R, Gillenwater A, Richards Kortum. Vision enhancement system for detection of oral cavity neoplasia based on autofluorescence. Head Neck 2004;26:205-215.

7. De Veld DC, Witjes MJ, Sterenborg HJ, Roodenburg JL. The status of in vivo autofluorescence spectroscopy and imaging for oral oncology. Oral Oncol 2005;41:117-131.

8. Poh CF, Zhang L, Anderson DW, Durham JS, Williams M, Priddy RW, et al.. Fluorescence visualization detection of field alterations in tumor margins of oral cancer patients. Clin Cancer Res 2006;12:6716-6722.

9. Fedele S. Diagnostic aids in the screening of oral cancer. Head Neck Oncol 2009;1:5.

10. Balevi B. Assessing the usefulness of three adjunctive diagnostic devices for oral cancer screening: a probabilistic approach. Community Dent Oral Epidemiol 2011;39:171-176

11. Mehrotra $R$, Singh $M$, Thomas $S$, Nair $P$, Pandya $S$, Nigam NS, et al.. A cross-sectional study evaluating chemiluminescence and autofluorescence in the detection of clinically innocuous precancerous and cancerous oral lesions. J Am Dent Assoc 2010;141:151-156.

12. Williams PM, Poh CF, Hovan AJ, Ng S, Rosin MP. Evaluation of a suspicious oral mucosal lesion. J Can Dent Assoc 2008;74:275-280.

13. Roed-Petersen B, Renstrup G. A topographical classification of the oral mucosa suitable for electronic data processing. Its application to 560 leukoplakias. Acta Odontol Scand 1969;27:681-695.

14. Newcombe RG. Two-sided confidence intervals for the single proportion: comparison of seven methods. Stat Med 1998;17:857872.

15. Bossuyt PM, Reitsma JB, Bruns DE, Gatsonis CA, Glasziou PP, Irwig LM, et al.. Towards complete and accurate reporting of studies of diagnostic accuracy: the STARD initiative. BMJ 2003;326:41-44.

16. Farah CS, McIntosh L, Georgiou A, McCullough MJ. Efficacy of tissue autofluorescence imaging (velscope) in the visualization of oral mucosal lesions. Head Neck 2012;34:856-862.

17. Gynther GW, Rozell B, Heimdahl A. Direct oral microscopy and its value in diagnosing mucosal lesions: a pilot study. Oral Surg Oral Med Oral Pathol Oral Radiol Endod 2000;90:164-170.

18. Balevi B. Evidence-based decision making: should the general dentist adopt the use of the VELscope for routine screening for oral cancer? J Can Dent Asso 2007;73:603-606. 
19. López-Jornet P, De la Mano-Espinosa T. The efficacy of direct tissue fluorescence visualization in screening for oral premalignant lesions in general practice: an update. Int J Dent Hyg 2011;9:97-100.

20. Hanken $H$, Kraatz J, Smeets $R$, Heiland $M$, Blessmann $M$, Eichhorn

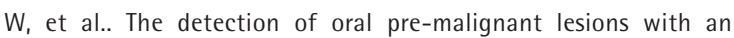
autofluorescence based imaging system (VELscopeTM) -- a single blinded clinical evaluation. Head Face Med. 2013;23;9-23.

21. McNamara KK, Martin BD, Evans EW, Kalmar JR. The role of direct visual fluorescent examination (VELscope) in routine screening for potentially malignant oral mucosal lesions. Oral Surg Oral Med Oral Pathol Oral Radiol 2012;114:636-643.

22. Nirav B, Yastira L, An N, Camile S. Advances in optical adjunctive aids for visualization and detection of oral malignant and potentially malignant lesions. Int J Dent 2013:194029.

Received August 5, 2014 Accepted September 11, 2015 